\title{
Multilevel Measures of Education and Pathways to Incident Herpes Simplex Virus Type 2 in Adolescent Girls and Young Women in South Africa
}

\author{
Marie C. D. Stoner, Ph.D. ${ }^{\text {a,* }}$, Torsten B. Neilands, Ph.D. ${ }^{b}$, Kathleen Kahn, Ph.D. ${ }^{\text {c, d,e }}$, \\ James P. Hughes, Ph.D. ${ }^{\text {f,g }}$, F. Xavier Gómez-Olivé, Ph.D. ${ }^{c, d}$, Rhian Twine, M.P.H. ${ }^{c}$, \\ Stephen Tollman, Ph.D. ${ }^{\mathrm{d}}$, Oliver Laeyendecker, Ph.D. ${ }^{\mathrm{h}}$, Catherine MacPhail, Ph.D. ${ }^{\mathrm{c}, \mathrm{i}, \mathrm{j}}$, \\ Jennifer Ahern, Ph.D. ${ }^{\mathrm{k}}$, Sheri A. Lippman, Ph.D. ${ }^{\mathrm{b}, \mathrm{c}}$, and Audrey Pettifor, Ph.D. ${ }^{\mathrm{a}, \mathrm{c}, \mathrm{l}}$ \\ ${ }^{a}$ Carolina Population Center, University of North Carolina, Chapel Hill, North Carolina \\ ${ }^{\mathrm{b}}$ Department of Medicine, University of California, San Francisco, San Francisco, California \\ ${ }^{\mathrm{c}}$ MRC/Wits Rural Public Health and Health Transitions Research Unit (Agincourt), School of Public Health, Faculty of Health Sciences, University of the Witwatersrand, \\ Johannesburg, South Africa \\ d INDEPTH Network, Accra, Ghana \\ ${ }^{\mathrm{e}}$ Epidemiology and Global Health Unit, Department of Public Health and Clinical Medicine, Umeå University, Umeå, Sweden \\ ${ }^{\mathrm{f}}$ Department of Biostatistics, University of Washington, Seattle, Washington \\ ${ }^{\mathrm{g}}$ Fred Hutchinson Cancer Research Center, Seattle, Washington \\ ${ }^{\mathrm{h}}$ Division of Intramural Research, National Institute of Allergy and Infectious Diseases, National Institutes of Health, Baltimore, Maryland \\ ${ }^{\mathrm{i}}$ School of Health and Society, University of Wollongong, New South Wales, Australia \\ ${ }^{\mathrm{j}}$ Wits Reproductive Health and HIV Research Institute, University of the Witwatersrand, Johannesburg, South Africa \\ ${ }^{\mathrm{k}}$ Division of Epidemiology, School of Public Health, University of California, Berkeley, Berkeley, California \\ ${ }^{1}$ Department of Epidemiology, University of North Carolina, Chapel Hill, North Carolina
}

Article history: Received February 12, 2019; Accepted June 24, 2019

Keywords: HSV-2; Mediation; Education; Sexual behaviors; Multilevel; Adolescent girls and young women

\section{A B S T R A C T}

Purpose: Schooling is associated with a lower risk of Herpes simplex virus type 2 (HSV-2) in adolescent girls and young women, but there is little understanding of the pathways underlying this relationship.

Methods: We used data from adolescent girls and young women in South Africa enrolled in the HIV Prevention Trials Network 068 study. We tested a structural equation model where individual household and community education measures were associated directly and indirectly with incident HSV-2 through HIV knowledge, future aspirations, age-disparate partnerships, sex in the last 12 months, and condomless sex.

Results: Community, household, and individual measures of schooling were all associated with incident HSV-2 infection through mediated pathways that increased the likelihood of having sex. Low school attendance ( $<80 \%$ of school days) increased the likelihood of having sex through increased age-disparate partnerships and reduced future aspirations. Fewer community years of education increased the likelihood of having sex through increased agedisparate partnerships. Parental education level was indirectly associated with HSV-2

\section{IMPLICATIONS AND CONTRIBUTION}

Community, household, and individual measures of education are associated with incident HSV-2 infection in adolescent girls and young women in South Africa. Lower mean year of education operates through increasing partner age and likelihood of having sex. Low school attendance operates through both increased
Conflicts of interest: The authors have no conflicts of interest to disclose. Disclaimer: The content is solely the responsibility of the authors and does not necessarily represent the official views of the National Institutes of Health. The authors thank the HPTN 068 study team and all trial participants.

\footnotetext{
* Address correspondence to: Marie C.D. Stoner, Ph.D., Carolina Population Center, University of North Carolina, 123 W. Franklin Street, Chapel Hill, NC 27599.

E-mail address: stonerm@email.unc.edu (M.C.D. Stoner).
} 
overall, although we could not identify the individual pathways that were responsible for this association.

Conclusions: Community and individual schooling interventions may reduce the risk of HSV-2 infection by influencing the likelihood of having sex, partner age, and future aspirations. partner age and low future aspirations.
Adolescent girls and young women (AGYW) in South Africa are disproportionately at risk of sexually transmitted infections (STIs) including Herpes simplex virus type 2 (HSV-2) and HIV. Patterns of HSV-2 prevalence show a strong differential by sex, with an estimated prevalence of $29 \%$ among young South African women compared with $10 \%$ in young South African men aged 15-26 years [1]. Risk of STIs in AGYW is strongly correlated with social and structural factors including gender inequity, stigma and discrimination (around HIV or access to health care), poverty, and education [2-4]. In our prior analyses among AGYW in South Africa, we found that low school attendance and school dropout were associated with over twice the risk of both incident HIV and HSV-2 [5]. Yet, there is limited research to provide a more in-depth understanding of this relationship, including determining whether household and community measures of education influence risk and examining the underlying pathways between schooling and HSV-2 infection.

\section{Connections of parental and community education with HSV-2 infection}

Individual education has been associated with both HSV-2 and HIV infection and is strongly correlated with parental and community education levels [6-8]. However, these measures have rarely been studied independently. Parental educational attainment is associated with socioeconomic disadvantage and a reduced prevalence of HIV [9]. At the community level, individual HIV knowledge can be increased through interaction with other community members with an equal or higher education level [10]. Negative gender norms are pervasive in many community settings in South Africa and have also been associated with access to education, intimate partner violence, and sexual behaviors [11-13]. Other measures that are correlated with community education such as community cohesion, group membership, and civic participation are associated with increased sexual behaviors among AGYW and with the risk of STIs [8,14-20].

\section{Mediators between education and HSV-2}

Research on pathways for the relationship between education at any level (individual, family, and community) and HSV-2 infection is similarly lacking. Our previous research from South Africa found that partner age difference and number of sexual partners both singly mediated the relationships between individual school attendance and incident HIV and HSV-2 infection [21]. Although that study provided some evidence that partner characteristics are important in the relationship between school attendance and HIV and HSV-2 infection, schooling is likely to influence other sexual behaviors. Furthermore, no studies have examined group-level education measures or other related mediators that have been hypothesized to be important in the relationship between education and HSV-2 infection, such as condomless sex and knowledge about sexual health, particularly when mediators are considered simultaneously.

We used a comprehensive review by Jukes et al. [22] to develop our theoretical model. Given the lack of research on HSV-2 and the similar pathways in the relationship between schooling and HIV infection, we used theoretical literature on HIV to guide our selection of mediators. We hypothesized that increased individual-level school attendance would be related to a reduced risk of incident HSV-2 through two distinct mediation steps whereby education first influences HIV knowledge, agedisparate partnerships, or future aspirations and, through these factors, affects sexual behavior (Figure 1). HIV knowledge will be used to test the common hypothesis that more educated individuals are more exposed to preventative information about STIs and may be more likely to change their behaviors to prevent infection [22-25]. Future aspirations will be used to determine if more educated individuals have different aspirations for the future, making them less inclined to engage in sexual activity that elevates exposure to STIs $[22,26,27]$. Finally, partner age difference is included to examine the idea that educated individuals have different social and sexual networks based on being in school that might make them less exposed to infection $[5,22]$. In the second mediation step, we will examine how the first-stage mediators influence sexual behaviors that can directly influence HSV-2 acquisition, including condomless sex and increased likelihood of sex in the last 12 months.

Overall, this study builds on our previous research by testing a structural equation model for the relationship between multilevel measures of education and risk of incident HSV-2 infection among AGYW in South Africa. First, we tested the global fit of our theory-based structural equation model to the available empirical data. Second, we examined if individual, household, and community measures of education were associated with risk of incident HSV-2. Third, we explored chained mediation pathways including through first-stage (HIV knowledge, future aspirations, and sexual networks) and second-stage (sex in the last 12 months and condomless sex) mediators (Figure 1).

\section{Methods}

\section{Study population}

We used longitudinal data from the HIV Prevention Trials Network (HPTN) 068 study in rural South Africa. HPTN 068 was a randomized trial to determine if providing cash transfers, conditional on school attendance, would reduce the incidence of HIV in AGYW [28,29]. The trial enrolled 2,533 AGYW in 2011 who were aged between 13 and 20 years, were not pregnant or married, had a parent/guardian in the household, and were enrolled in grades $8-11$. The study included AGYW living in 28 villages within the MRC/Wits Rural Public Health and Health 
Transitions Research Unit (Agincourt) in rural Mpumalanga Province, South Africa. The area is the site of the Agincourt Health and Socio-Demographic Surveillance Site, which includes an annual census of more than 115,000 people. The area is rural with little infrastructure, high levels of poverty, unemployment, and migration and high levels of social protection (80\% receiving the child support grant) [30]. We included girls who were HIV and HSV-2 negative at baseline and had at least two annual follow-up visits to examine mediation, ensure temporal ordering, and isolate incident infections [29].

Young women were randomized 1:1 to the control or intervention arm and were followed annually from enrollment until study completion (up to 3 years in 2015) or graduation from high school, whichever came first. Young women remained in the study if they dropped out of school, were married, or became pregnant. Each annual visit included an Audio ComputerAssisted Self-Interview survey and a test for HIV/HSV-2 for those who previously tested negative. Institutional review board approval was obtained from the University of North Carolina at Chapel Hill and the University of the Witwatersrand Human Research Ethics Committee as well as the Provincial Department of Health's Research Ethics Committee.

\section{Ascertainment of exposures, outcome, mediators, and covariates}

The main exposure of time-varying, individual school attendance was defined as the percentage of school days attended in the months between study visits based on high school attendance registers $[5,29]$. The exposure was dichotomized as high ( $\geq 80 \%$ school days) versus low attendance ( $<80 \%$ school days), using the cutoff from the cash transfer intervention $[5,28]$. Other multilevel measures of education included baseline parental level of education and time-varying community mean years of education (based on reported village if the girl moved). Parental education was a categorical variable defined using four categories: no school, primary school, some secondary school, and completed secondary or higher education. Mother's educational level was used unless the mother had died, in which case father's educational level was used. Mean community years of education was a continuous variable created using village-level information from the Agincourt HDSS census about the village where the girl reported currently living [30]. This variable was constructed as the mean of the total years of education reported by all individuals living in a specific village. The outcome of incident HSV-2 infection was defined as new cases of HSV-2 detected following enrollment [28].

The time-varying mediators that were examined in our study were future aspirations (hope for the future), condomless sex in the last 3 months, age-disparate partnerships (partner aged $\geq 5$ years), having sex in the last 12 months, and HIV knowledge (Figure 1). Hope for the future was a continuous variable constructed using a scale that was created and validated using the HPTN 068 cohort [31]. The hope for the future scale consists of 12 items with a 4-point Likert response from "1" for totally disagree to "4" for totally agree. All sexual behaviors were self-reported. Condomless sex in the last 3 months was defined as not using a condom at the last vaginal or anal sex. Having an age-disparate partnership was defined as having at least one sexual or nonsexual partner $\geq 5$ years older. This categorization has been used in prior HPTN 068 analyses and is conventional in the literature [32]. Condomless sex and sex in the last 12 months were coded as 0 if the girl did not have sex in the last 12 months, and partner age was coded as 0 if she did not report a partner. HIV knowledge score was used as a proxy for general knowledge about the prevention of STIs and was defined as the number of questions answered correctly using a six-question scale [33]. HIV knowledge was dichotomized as answering more than $50 \%$ of questions correctly versus less than $50 \%$. Mediators were ascertained from the time point after exposures and before the outcome ascertainment.

Covariates that were included in all models were age at baseline, intervention assignment at baseline, and baseline socioeconomic status (SES). SES was constructed using principal components analysis with assets and divided into quartiles. Age was selected as a covariate as it is one of the strongest factors related to risk of HSV-2 infection [34], and SES was selected as it is closely linked to education level [22]. Randomization arm was included in all models to account for the original study design of the randomized trial.

\section{Statistical analysis}

We used structural equation modeling in Mplus version 8.1 (Muthén \& Muthén, Los Angeles, CA) to test our model for the relationship between multilevel measures of education and risk of HSV-2 infection including through all mediators (Figure 1). We used a discrete-time survival model with the Mplus Bayes estimator and noninformative priors before examining mediation paths. The Bayesian estimator was used instead of other available estimation options (e.g., maximum likelihood) because it simultaneously (1) includes cases with partial data, (2) allows for correlated residuals among the multiple mediators, (3) computes optimal asymmetric credible intervals [CIs] (the Bayesian analog of confidence intervals used in frequentist statistics) for indirect effects, (4) allows for multiple mediators in a sequential arrangement (chained mediation), and (5) can be used to test a specific model within the structural equation modeling framework [35]. For continuous mediators, the model uses a normal distribution; for binary mediators and the HSV-2 outcome, a probit distribution with underlying latent variables with a standard normal residual distribution is assumed. Therefore, the coefficients $(B)$ represent linear regression coefficients between exposures and the underlying latent representations for binary variables, including HSV-2 (i.e., the change in the continuous underlying latent variable per 1-unit change in the exposure). We report standardized coefficients and 95\% credible intervals $(\mathrm{CI})$. Global model fit for the proposed standard error of the mean (SEM) was assessed using the posterior predictive $p$ (PPP) value. PPP values close to .50 indicate excellent model-data fit, whereas PPP values close to 0 or 1 indicate poorer fit [36].

We estimated both the indirect association through each of the mediated paths and the direct association not through each mediator for each exposure [37]. To account for the sequence of mediators, we modeled first-stage mediators (knowledge, hope for the future, and age-disparate partner), second-stage mediators affected by first stage mediators (sex in the last 12 months and condomless sex) and then HSV-2 affected by all mediators. Covariates were included in the model for the first-stage mediators and the outcome.

\section{Results}

Of the 2,533 young women enrolled in the original trial, we included 1,691 girls who were HSV-2 and HIV negative at baseline and had at least three visits (at baseline and two follow-up 
visits later). There were 120 incident HSV-2 infections over the study period in 6,723 study visits. At baseline, the median age was 15 years (interquartile range 14-16), 3.7\% had an agedisparate partnership, $19.5 \%$ had sex in the last 12 months, $60.0 \%$ had a low hope for the future score (below median of 35 ), $63.0 \%$ had low HIV knowledge, $5 \%$ had condomless sex in the last 3 months, and $96.6 \%$ had high attendance in school (>80\% school days; Table 1 ). About $17 \%$ had a parent with no education, and the mean years of community education was 6.6 , representing the completion of some primary school. Over the entire study period, girls reported having a partner in the last 12 months at $29.2 \%$ of visits, an older partner at $6.5 \%$ of visits, and unprotected sex at $7.8 \%$ of visits.

For the specified structural equation model, the PPP value was .30, indicating satisfactory global model-data fit [36]. The percent of the variance in HSV-2 explained by the model was $21.9 \%$ (95\% CI: $13.3 \%-31.5 \%$ ). Table 2 shows associations for the first step of the chained mediation pathway, examining how multilevel exposures of education affect first-stage mediators (low hope for the future, HIV knowledge, and age-disparate partnerships). At the individual level, young women with low school attendance had a lower hope for the future (B: $-.12 ; 95 \% \mathrm{CI}:-.09$ to -.15 ) and had a higher propensity of having an age-disparate partnership ( $B: .15$; 95\% CI .11-.18). At the household level, young women with a parent with some secondary $(B$ : $-.04 ; 95 \% \mathrm{CI}-.01$ to -.08$)$ and primary education $(B$ : $-.05 ; 95 \% \mathrm{CI}-.01$ to -.08 ) had lower hope for the future, compared with a parent who had completed secondary education. At the community level, lower mean years of education was associated with a higher propensity of having an age-disparate partnership ( $B$ : .08 per 1-year decrease in mean education; 95\% CI: .04-.12).

Table 3 shows associations between the first-stage mediators (hope for the future, HIV knowledge, and age-disparate partnerships) and second-stage mediators (condomless sex and sex in the last 12 months). All first-stage mediators were associated with sex in the last 12 months. Low hope for the future and agedisparate partnerships were associated with condomless sex, whereas HIV knowledge was not.

Table 4 shows the third step of the mediation chain examining associations between the second-stage mediators (condomless sex and sex in the last 12 months) and incident HSV-2 infection. Young women who had sex in the last 12 months had a .53 higher propensity of HSV-2 infection (95\% CI .23-.82). However, condomless sex was not associated with an increased incidence of HSV-2 ( $B$ : .27\%; 95\% -.04 to .57).

Overall, all three multilevel measures of education were indirectly associated with incident HSV-2 infection through our mediators of interest (Table 5). At the individual level, lower school attendance was associated with a higher propensity of HSV-2 indirectly ( $B$ : .04; 95\% CI .02, .06) and overall $(B .09 ; 95 \% \mathrm{Cl}$ $.02, .16$; Table 5 ). At the household level, compared to having a parent that completed secondary school, we found an indirect association for not completing secondary school on HSV-2 ( $B$ : $.01 ; 95 \%$ CI .00-.02). At the community level, a 1-year decrease in the mean level of village education was associated with a .01 (95\% CI .01-.35) increase in the underlying propensity of HSV-2 infection. We did not identify a total association between community education and HSV-2. In this instance, the total association could be null because these associations operated in opposite directions and therefore could have canceled each other out (Table 5) [38].

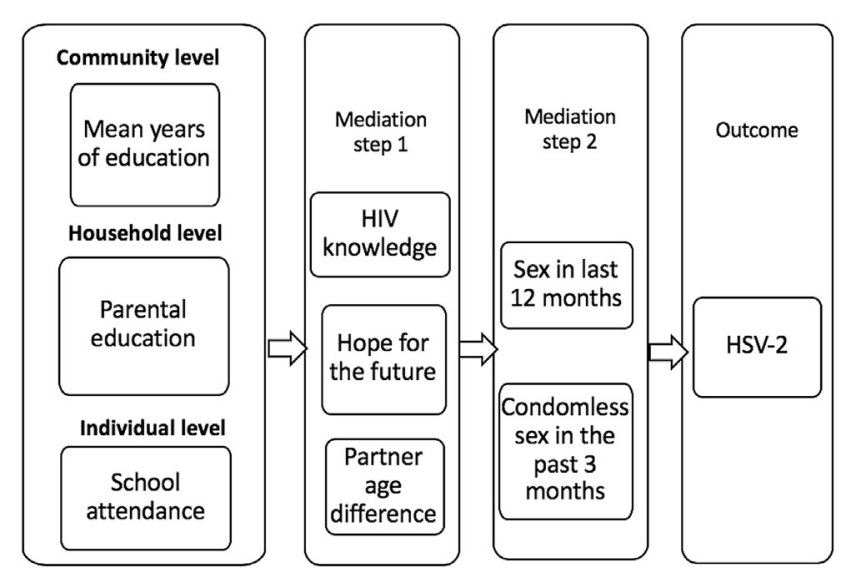

Figure 1. Conceptual model of individual, household and community measures of education leading to HSV-2 infection in young women*. This is a conceptual model and not an analytic model (e.g., DAG or SEM graph). Covariates (not shown in diagram for clarity): age, SES, intervention randomization arm. *Definitions: Low school attendance $<80 \%$ of school days, age-disparate relationship (partner aged $\geq 5$ years), low HIV knowledge ( $\leq 50 \%$ correct); Community mean years of education. HSV-2, Herpes simplex virus type 2.

Figure 2 shows the chained (sequential) mediation pathways for the indirect associations between each measure of education and incident HSV-2 infection. Low school attendance increased incident HSV-2 infection by increasing the propensity of an agedisparate partnership ( $B$ : .05; 95\% CI .02-.09) and increasing

Table 1

Baseline characteristics of young women aged 13-20 without prevalent HSV-2 infection and at least three follow-up visits in Agincourt, South Africa, from March 2011 to December $2012(\mathrm{~N}=1,691)$

\begin{tabular}{|c|c|c|}
\hline & $\mathrm{n}(\%)$ & Median (IQR) \\
\hline Young women's age at baseline (y) & & $15(14-16)$ \\
\hline $13-14$ & $685(40.5)$ & \\
\hline $15-16$ & $772(45.6)$ & \\
\hline $17-18$ & $203(12.0)$ & \\
\hline $18-20$ & $31(1.8)$ & \\
\hline High attendance in school $(\geq 80 \%)$ & $1,624(96.6)$ & \\
\hline \multicolumn{3}{|l|}{ Household wealth } \\
\hline Low & $428(25.3)$ & \\
\hline Middle to low & $5,466(25.3)$ & \\
\hline Middle & $400(23.7)$ & \\
\hline High & $395(23.4)$ & \\
\hline \multicolumn{3}{|l|}{ Parental education at baseline (household) } \\
\hline No school & $258(16.8)$ & \\
\hline Primary school & $371(24.2)$ & \\
\hline Some secondary school & $467(30.4)$ & \\
\hline Completed secondary or higher & $440(28.7)$ & \\
\hline Community mean years of education & & $6.6(6.1-6.9)$ \\
\hline Community max years of education & & $8(7-8)$ \\
\hline Hope for the future score (continuous) & & $32(26-38)$ \\
\hline Low hope for the future score (below median) & $1,006(60.0)$ & \\
\hline Low HIV knowledge ( $\leq 50 \%$ correct $)$ & $1,042(63.0)$ & \\
\hline Sex in the last $12 \mathrm{mo}$ & 327 (19.5) & \\
\hline Age-disparate relationship (partner aged $\geq 5 \mathrm{y}$ ) & $60 .(3.7)$ & \\
\hline Ever had sex & $318(18.8)$ & \\
\hline Any condomless sex in last $3 \mathrm{mo}$ & $84(5.0)$ & \\
\hline CCT randomization arm & $912(53.9)$ & \\
\hline
\end{tabular}

Total $\mathrm{N}=1,691$; missing: age 0 ; randomization arm 0 ; SES 2; age difference 55 ; sex in last 12 months 15; school attendance 10; physical violence 37; ever had sex 2, partner in last 12 months 15 ; HIV knowledge 38 ; hope for the future 16; parental education 155; condomless sex 13

HSV-2 = Herpes simplex virus type $2 ; \mathrm{IQR}=$ interquartile range. 
Table 2

Linear regression coefficients (B) and 95\% credible intervals (CIs) for the associations in step 1 of the mediation pathway ${ }^{a}$

\begin{tabular}{|c|c|c|c|}
\hline \multirow[t]{3}{*}{ Exposures } & \multicolumn{3}{|l|}{ Outcome } \\
\hline & Hope for the future & Older partner & Knowledge \\
\hline & $B(95 \% \mathrm{CI})$ & $B(95 \% \mathrm{CI})$ & $B(95 \% \mathrm{CI})$ \\
\hline $\begin{array}{l}\text { Low attendance } \\
\text { Household-level } \\
\text { education }\end{array}$ & $-.12(-.09,-.15)$ & $.15(.11, .18)$ & $-.00(-.05, .05)$ \\
\hline No school & $.01(-.03, .04)$ & $.01(-.05, .06)$ & $.03(-.04, .10)$ \\
\hline Primary school & $-.05(-.01,-.08)$ & $.03(-.02, .09)$ & $.03(-.04, .10)$ \\
\hline $\begin{array}{l}\text { Some secondary } \\
\text { school }\end{array}$ & $-.04(-.01,-.08)$ & $.05(-.00, .11)$ & $-.01(-.07, .06)$ \\
\hline $\begin{array}{l}\text { Completed } \\
\text { secondary }\end{array}$ & $\mathbf{0}$ & 0 & 0 \\
\hline $\begin{array}{l}\text { Mean years of } \\
\text { community } \\
\text { education }\end{array}$ & $-.02(-.05, .01)$ & $.08(.04, .12)$ & $.04(-.04, .08)$ \\
\hline
\end{tabular}

hope for the future $(B: .003 ; 95 \% \mathrm{CI} .001-.01)$, which then increased sex in the last 12 months. At the household level, we did not identify any specific pathways. At the community level, a 1-year decrease in the mean level of education was associated with a higher propensity of incident HSV-2 infection because young women were more likely to have an age-disparate partnership and then more likely to have sex in the last 12 months ( $B$ : .03 ; $95 \%$ CI .01-.05).

\section{Discussion}

Low attendance in school, lower community mean years of education, and lower parental level of education were all indirectly associated with $\mathrm{HSV}-2$ infection through mediation. Sequential mediation pathways ultimately operated through an increased likelihood of having sex. Low school attendance increased the probability of having sex through reduced future aspirations and increased age-disparate partnerships. Lower community years of education increased probability of sex through increased age-disparate partnerships. Lower parental education level was associated with HSV-2 through mediators, although we could not identify the individual pathways that were responsible for this association.

Our results are consistent with prior studies showing a strong relationship between individual school attendance and HSV-2 infection $[2,5]$ and identifying that this relationship operates through increased age-disparate partnerships and likelihood of having sex [21]. However, we further identify multistep mediation pathways underlying these associations and show that both

Table 3

Associations for step 2 of the mediation pathway

\begin{tabular}{|c|c|c|}
\hline \multirow[t]{3}{*}{ Exposures } & \multicolumn{2}{|l|}{ Outcome } \\
\hline & Condomless sex & Sex in the last $12 \mathrm{~m}$ \\
\hline & $B(95 \% \mathrm{CI})$ & $B(95 \% \mathrm{CI})$ \\
\hline Hope for the future & $-.10(-.15,-.05)$ & $-.06(-.10,-.02)$ \\
\hline Partner age difference ( $\geq 5 \mathrm{y}$ ) & $-.50(-.55,-.45)$ & $.68(.64, .72)$ \\
\hline HIV knowledge & $-.02(-.11,-.06)$ & $.16(.08, .23)$ \\
\hline
\end{tabular}

Bold values are $p<0.05$.

$\mathrm{CI}=$ confidence interval.
Table 4

Associations for step 3 of the mediation pathway

\begin{tabular}{ll}
\hline Exposures & $\frac{\text { Outcome }}{\mathrm{HSV}-2}$ \\
& $\frac{B(95 \% \mathrm{CI})}{}$ \\
\hline Condomless Sex & $.27(-.04, .57)$ \\
Sex in the last 12 mo & $\mathbf{. 5 3}(. \mathbf{2 3}, \mathbf{. 8 2})$ \\
\hline
\end{tabular}

$\mathrm{N}=6,723$ person-time observations from 1,691 participants.

Bold values are $p<0.05$.

$\mathrm{CI}=$ confidence interval; HSV-2 = Herpes simplex virus type 2 .

a Adjusted for low attendance, household-level education, community mean education, socioeconomic status, age, randomization arm.

increased age-disparate partnerships and reduced hope for the future increase likelihood of having sex and risk of HSV-2. Our results support previous findings that school attendance may prevent HIV and HSV-2 by reducing opportunities for sexual activity and encouraging partnerships with same-age peers rather than older partners when sexual activity does occur [21]. However, we add to these findings with evidence to support the hypothesis that young women who are in school have different aspirations for the future that reduce risk of HSV-2, in this case by reducing likelihood of having sex $[26,27,39]$. Structural interventions to increase individual school attendance make AGYW feel more hopeful about the future, changing sexual behavior. Building positive future aspirations is particularly critical for AGYW in contexts such as the ADHSS area, where there are limited opportunities for employment or higher education and AGYW may feel pressure to start a family. In addition, the indirect association between parental education and HSV-2 highlights the importance of positive role models and support for young women, which can increase individual aspirations to complete school $[6,7]$.

\section{Table 5}

Linear regression coefficients (B) and 95\% credible intervals (CIs) for the total, direct, and total indirect associations of each multilevel exposure of education with incident HSV-2 infection ${ }^{a}$

\begin{tabular}{|c|c|c|c|}
\hline & Total & Total indirect & Direct \\
\hline & $\begin{array}{l}B \\
(95 \% \mathrm{CI})\end{array}$ & $\begin{array}{l}B \\
(95 \% \mathrm{CI})\end{array}$ & $\begin{array}{l}B \\
(95 \% \mathrm{CI})\end{array}$ \\
\hline $\begin{array}{l}\text { Community: } \\
\text { mean years } \\
\text { of education }\end{array}$ & $-.01(-.08, .07)$ & $.02(.01, .03)$ & $-.03(-.10, .05)$ \\
\hline \multicolumn{4}{|l|}{$\begin{array}{l}\text { Household: } \\
\text { parental } \\
\text { level } \\
\text { of education }\end{array}$} \\
\hline No school & $-.01(-.11, .08)$ & $.00(-.01, .23)$ & $-.02(-.12, .08)$ \\
\hline Primary school & $-.11(-.22,-.001)$ & $.01(.00, .03)$ & $-.12(-.23,-.01)$ \\
\hline $\begin{array}{l}\text { Some secondary } \\
\text { school }\end{array}$ & $-.04(-.14, .06)$ & $.01(.00, .02)^{b}$ & $-.05(-.15, .05)$ \\
\hline $\begin{array}{l}\text { Completed } \\
\text { secondary } \\
\text { (ref) }\end{array}$ & 0 & $\mathbf{0}$ & $\mathbf{0}$ \\
\hline $\begin{array}{l}\text { Individual: Low } \\
\text { school } \\
\text { attendance }\end{array}$ & $.09(.02, .16)$ & $.04(.02, .06)$ & $.05(-.02, .12)$ \\
\hline
\end{tabular}

HSV-2 = Herpes simplex virus type 2.

a Bold value represents is $p \leq .05 ; \mathrm{N}=6,723$ person-time observations from 1,691 participants.

${ }^{\mathrm{b}}$ Lower bound is .001 due appears as .00 due to rounding. 


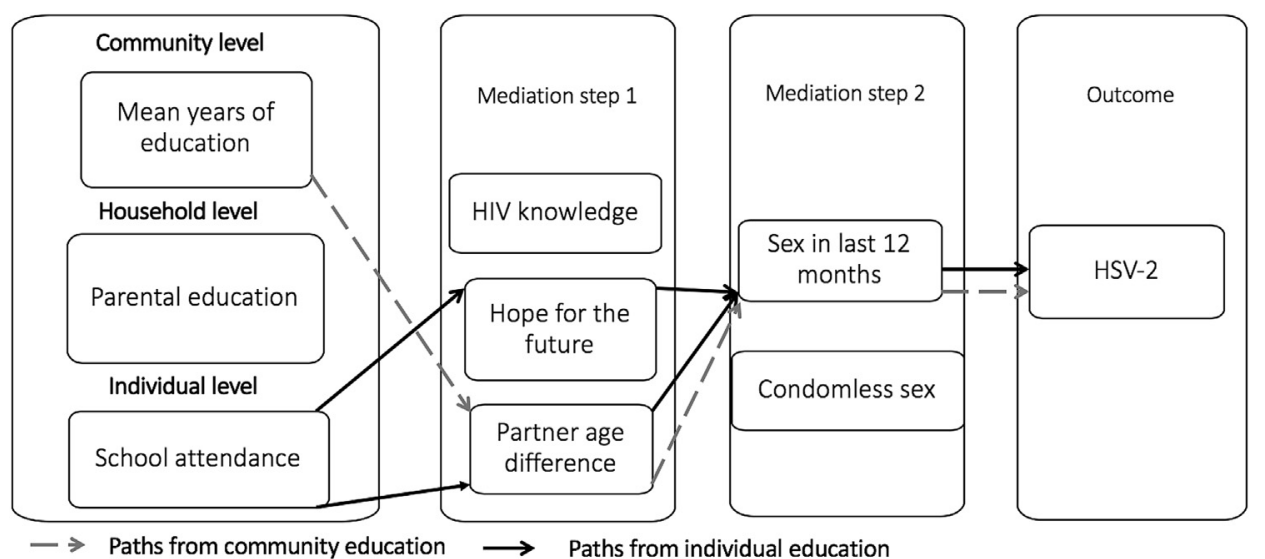

Figure 2. Significant pathways for the effect of multilevel measures of schooling on incident HSV-2 infection*. *All paths were significant at alpha $<.05$; Path for mean community level of education (B: .03; 95\% CI .01-.05); Path for school attendance through future aspirations (B: .00; $95 \% \mathrm{CI} .00-.01)$; path for school attendance through partner age ( $B: .05 ; 95 \% \mathrm{CI} .02-.09) ; \mathrm{N}=6,723$ person-time observations from 1,691 participants. ${ }^{*}$ Definitions: low school attendance $<80 \%$ of school days, age-disparate relationship (partner aged $\geq 5$ years), low HIV knowledge ( $\leq 50 \%$ correct); Community mean years of education. HSV-2, Herpes simplex virus type 2

We identified an indirect association between decreased community mean years of education and increased incidence of HSV-2 infection that operated through an increased probability of having an age-disparate partnership. These findings could be related to men in more education communities perceiving risk to be higher in relationships with younger women and not engaging in these relationships [40]. Or, community education may be a marker for other community-level variables that affect HSV-2 acquisition such as gender norms, community cohesion, group participation, and stigma and discrimination, which are related to HIV risk [8,14-20]. More research is needed regarding how these other factors correlate with community-level education to understand how to best intervene, but we do see that agedisparate relationships, a strong determinant of HIV risk, can be changed through community-level characteristics.

Our study is one of the first to investigate chained mediation pathways that involve multiple factors in the relationship between multilevel measures of education and incident HSV-2 However, many of the mediators of this relationship are selfreported sexual behaviors, which may have resulted in underreporting, socially desirable reporting, or recall biases. Second, to examine mediation, our sample was limited to participants who had at least two follow-up visits, and participants may be older. In addition, the use of three visits limited our power to examine incident HIV infection, and therefore, only incident HSV-2 was examined as an outcome. Given our specification of a model with relatively few covariates, it is also possible that we are not including important confounders. We did not explicitly model loss to follow-up in the analysis, but retention was high in the study (87\% control and 95\% intervention) [29]. The remaining few cases with partial data were included in the structural equation modeling under the relatively mild conditionally missing at random assumption via Bayesian estimation. Finally, we used a comprehensive review by Jukes et al. [22] to develop our theoretical model for the relationship between education and HIV infection and therefore assume that pathways in that review are most likely.

We used the Bayesian SEM approach implemented in Mplus because it was the only approach that allowed us to test an
SEM with multiple, sequential mediators and assess model fit. However, this approach is limited to interpretability. In addition, the associations obtained are not estimates of parameters that can be defined as hypothetical interventions, as they would be if using a causal inference framework, obtaining estimates of parameters that correspond to hypothetical interventions in the context of complex SEMs with multiple sequential mediators is an area of ongoing research. Finally, our method assumes that there is no interaction between exposure and mediator.

In conclusion, household, community, and individual measures of schooling were associated with incident HSV-2 infection among AGYW, and this relationship primarily operated through likelihood of having sex. Low attendance in school led to both increased age-disparate partnerships and reduced aspirations for the future, which increased the likelihood of having sex. Lower community education influenced HSV-2 through increased age-disparate relationships. Structural interventions to increase access to education are important to elevate future aspirations and decrease age-disparate partnerships, thus reducing risk of $\mathrm{HSV}-2$ infection. In addition, increasing the community level of education could be a way to reduce the risk of STIs in young women by reducing age-disparate partnerships.

\section{Funding Sources}

This study was funded by the National Institutes of Health (NIH; R01MH087118 and R01 MH110186) and by Award Numbers UM1 AI068619 (HPTN Leadership and Operations Center), UM1AI068617 (HPTN Statistical and Data Management Center), and UM1AI068613 (HPTN Laboratory Center) from the National Institute of Allergy and Infectious Diseases (NIAID), the National Institute of Mental Health, and the National Institute on Drug Abuse of the National Institutes of Health (NIH). Additional support was provided by the Division of Intramural Research, NIAID, NIH. This work was also supported by the Carolina Population Center and its NIH grant (P2C HD050924). The MRC/Wits Rural Public Health and Health Transitions Research Unit and 


\section{Agincourt Health and Socio-Demographic Surveillance System have been supported by the University of the Witwatersrand, the Medical Research Council, South Africa, and the Wellcome Trust, UK (058893/Z/99/A, 069683/Z/02/Z, 085477/Z/08/Z, 085477/B/ 08/Z).}

\section{References}

[1] Jewkes R, Wood K, Duvvury N. "I woke up after I joined stepping stones": Meanings of an HIV behavioural intervention in rural South African young people's lives. Health Educ Res 2010;25:1074-84.

[2] Pettifor AE, Levandowski BA, Macphail C, et al. Keep them in school: The importance of education as a protective factor against HIV infection among young South African women. Int J Epidemiol 2008;37:1266-73.

[3] Harrison A, Colvin CJ, Kuo C, et al. Sustained high HIV incidence in young women in Southern Africa: Social, behavioral, and structural factors and emerging intervention approaches. Curr HIV/AIDS Rep 2015;12:207-15.

[4] Pettifor A, Stoner M, Pike C, et al. Adolescent lives matter: Preventing HIV in adolescents. Curr Opin HIV AIDS 2018;13:265-73.

[5] Stoner MCD, Pettifor A, Edwards JK, et al. The effect of school attendance and school dropout on incident HIV and HSV-2 among young women in rural South Africa enrolled in HPTN 068. AIDS 2017;31:2127-34.

[6] Dubow EF, Boxer P, Huesmann LR. Long-term effects of parents' education on children's educational and success: Mediation by family interactions, child aggression, and teenage aspirations. Merrill Palmer Q 2009;55:224-49.

[7] Dickson M, Gregg P, Robinson H. Early, late or never? When does parental education impact child outcomes? Econ J 2016;126:F184-231.

[8] Gregson S, Terceira N, Mushati P, et al. Community group participation: Can it help young women to avoid HIV? An exploratory study of social capital and school education in rural Zimbabwe. Soc Sci Med 2004:58:2119-32.

[9] Bärnighausen T, Hosegood V, Timaeus IM, et al. The socioeconomic determinants of HIV incidence: Evidence from a longitudinal, populationbased study in rural South Africa. AIDS 2007:21 Suppl 7:S29-38.

[10] World Food Program. Literature review on the impact of education level on HIV/AIDs prevalence rates. Rome, Italy: World Food Program; 2006.

[11] Pulerwitz J, Barker G. Measuring attitudes toward gender norms among young men in Brazil: Development and psychometric evaluation of the GEM scale. Men Masculinities 2008;10:322-38.

[12] Greig A, Peacock D, Jewkes R, et al. Gender and AIDS: Time to act. AIDS 2008;22 Suppl 2:S35-43.

[13] Seth P, DiClemente RJ, Lovvorn AE. State of the evidence: Intimate partner violence and HIV/STI risk among adolescents. Curr HIV Res 2013:11:528-35.

[14] Jennings JM, Hensel DJ, Tanner AE, et al. Are social organizational factors independently associated with a current bacterial sexually transmitted infection among urban adolescents and young adults? Soc Sci Med 2014; 118:52-60.

[15] Crosby RA, Holtgrave DR, DiClemente RJ, et al. Social capital as a predictor of adolescents' sexual risk behavior: A state-level exploratory study. AIDS Behav 2003; 7:245-52.

[16] Youngblade LM, Curry LA, Novak M, et al. The impact of community risks and resources on adolescent risky behavior and health care expenditures. J Adolesc Health 2006;38:486-94.

[17] Gregson S, Mushati P, Grusin H, et al. Social capital and women's reduced vulnerability to HIV infection in rural Zimbabwe. Popul Dev Rev 2011:37:333-59.

[18] Kerrigan D, Witt S, Glass B, et al. Perceived neighborhood social cohesion and condom use among adolescents vulnerable to HIV/STI. AIDS Behav 2006;10:723-9.
[19] Pronyk PM, Harpham T, Morison LA, et al. Is social capital associated with HIV risk in rural South Africa? Soc Sci Med 2008;66:1999-2010.

[20] Browning CR, Leventhal T, Brooks-Gun J. Sexual initiation in early adolescence: The Nexus of parental and community control. Am Sociol Rev 2005; 70:758-78.

[21] Stoner MC, Pettifor A, Eduwards JK, et al. Does partner selection mediate the relationship between school attendance and HIV/HSV-2 among adolescent girls and young women in South Africa: An analysis of HPTN 068 data. J Acquir Immune Defic Syndr 2018;79:20-7.

[22] Jukes M, Simmons S, Bundy D. Education and vulnerability: The role of schools in protecting young women and girls from HIV in southern Africa. AIDS 2008;22 Suppl 4:S41-56.

[23] Gregson S, Zhuwau T, Anderson RM, et al. Is there evidence for behaviour change in response to aids in rural Zimbabwe? Soc Sci Med 1998; $46: 321-30$

[24] Rosenstock IM. The health belief model: Explaining health behavior through expectancies. Heal Behav Health Educ 1990:39-61.

[25] Ajzen I. Perceived behavioral control, self-efficacy, locus of control, and the theory of planned behavior. J Appl Soc Psychol 2002;32:665-83.

[26] Kirby D. The impact of schools and school programs upon adolescent sexual behavior. J Sex Res 2002;39:27-33.

[27] de Walque D. How does the impact of an HIV/AIDS information campaign vary with educational attainment? Evidence from rural Uganda. J Dev Econ 2007;84:686-714.

[28] Pettifor A, MacPhail C, Selin A, et al. HPTN 068: A randomized control trial of a conditional cash transfer to reduce HIV infection in young women in South Africa-Study design and baseline results. AIDS Behav 2016;20:1863-82.

[29] Pettifor A, MacPhail C, Hughes JP, et al. The effect of a conditional cash transfer on HIV incidence in young women in rural South Africa (HPTN 068): A phase 3, randomised controlled trial. Lancet Glob Health 2016;4:e978-88.

[30] Kahn K, Collinson MA, Xavier Gómez-olivé F, et al. Profile: Agincourt health and socio-demographic surveillance system. Int J Epidemiol 2012;41:9881001.

[31] Abler L, Hill L, Maman S, et al. Hope matters: Developing and validating a measure of future expectations among young women in a high HIV prevalence setting in rural South Africa (HPTN 068). AIDS Behav 2017;21:2156-66.

[32] Stoner MCD, Nguyen N, Kilburn K, et al. Age-disparate partnerships and incident HIV infection in adolescent girls and young women in rural South Africa: An HPTN 068 analysis. AIDS 2019;33:83-91.

[33] Bowen P, Govender R, Edwards P. Validating survey management scales for AIDS-related knowledge and stigma among construction workers in South Africa. BMC Public Health 2016;16:1-13.

[34] Smith JS, Robinson NJ. Age-specific prevalence of infection with herpes simplex virus types 2 and 1: A global review. J Infect Dis 2002;186 Suppl: S3-28.

[35] Yuan Y, MacKinnon DP. Bayesian mediation analysis. Psychol Methods 2009:14:301-22.

[36] Muthén B, Asparouhov T. Bayesian structural equation modeling: A more flexible representation of substantive theory. Psychol Methods 2012;17: 313-35.

[37] Muthén B, Asparouhov T. Causal effects in mediation modeling: An introduction with applications to latent variables. Struct Equ Model 2015;22: $12-23$.

[38] MacKinnon DP, Fairchild AJ, Fritz MS. Mediation analysis. Annu Rev Psychol 2007;58:593-614.

[39] Frye M. Bright futures in Malawi's new dawn: Educational aspirations as assertions of identity. Am J Sociol 2012;117:1565-624.

[40] Cockcroft A, Kunda JL, Kgakole L, et al. Community views of intergenerational sex: Findings from focus groups in Botswana, Namibia and Swaziland. Psychol Health Med 2010;15:507-14. 